\title{
Ultrasensitive binder-free glucose sensors based on the pyrolysis of in situ grown $\mathrm{Cu}$ MOF
}

Zhang, Xuan ; Luo, Jiangshui; Tang, Pengyi ; Morante, Joan Ramon; Arbiol, Jordi; Xu, Cailing ; Li, Qingfeng; Fransaer, Jan

\section{Published in:}

Sensors and Actuators B: Chemical

Link to article, DOI:

10.1016/j.snb.2017.07.024

Publication date:

2017

Document Version

Peer reviewed version

Link back to DTU Orbit

Citation (APA):

Zhang, X., Luo, J., Tang, P., Morante, J. R., Arbiol, J., Xu, C., Li, Q., \& Fransaer, J. (2017). Ultrasensitive binderfree glucose sensors based on the pyrolysis of in situ grown Cu MOF. Sensors and Actuators B: Chemical, 254, 272-281. https://doi.org/10.1016/j.snb.2017.07.024

\section{General rights}

Copyright and moral rights for the publications made accessible in the public portal are retained by the authors and/or other copyright owners and it is a condition of accessing publications that users recognise and abide by the legal requirements associated with these rights.

- Users may download and print one copy of any publication from the public portal for the purpose of private study or research.

- You may not further distribute the material or use it for any profit-making activity or commercial gain

- You may freely distribute the URL identifying the publication in the public portal 


\section{Ultrasensitive binder-free glucose sensors based on the pyrolysis of in situ grown $\mathrm{Cu}$ MOF*}

\section{Xuan Zhanga, Jiangshui Luo ${ }^{a^{*}}$, Pengyi Tang ${ }^{b, c}$, Joan Ramon Morante ${ }^{b, c}$, Jordi Arbiol ${ }^{b, d *}$, Cailing Xu ${ }^{\mathrm{e}}$, Qingfeng Lif, Jan Fransaer ${ }^{\mathrm{a}^{*}}$}

* Dedicated to Prof. Deyue Yan

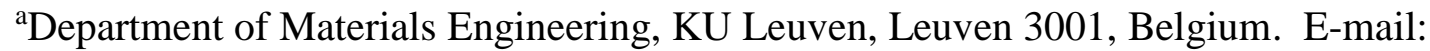
jan.fransaer@mtm.kuleuven.be; jiangshui.luo@kuleuven.be

${ }^{\mathrm{b}}$ Catalan Institute of Nanoscience and Nanotechnology (ICN2), CSIC and The Barcelona Institute of Science and Technology (BIST), Campus UAB, Bellaterra, 08193 Barcelona, Catalonia, Spain. E-mail: arbiol@icrea.cat

${ }^{c}$ Catalonia Institute for Energy Research (IREC), Jardins de les Dones de Negre 1, Sant Adrià del Besòs, 08930 Barcelona, Catalonia, Spain

${ }^{\mathrm{d} I C R E A, ~ P g . ~ L l u i ́ s ~ C o m p a n y s ~ 23, ~} 08010$ Barcelona, Catalonia, Spain

${ }^{\mathrm{e}}$ Key Laboratory of Nonferrous Metal Chemistry and Resources Utilization of Gansu Province, College of Chemistry and Chemical Engineering, Lanzhou University, Lanzhou 730000, China.

fDepartment of Energy Conversion and Storage, Technical University of Denmark, Kgs. Lyngby 2800, Denmark.

Graphical abstract

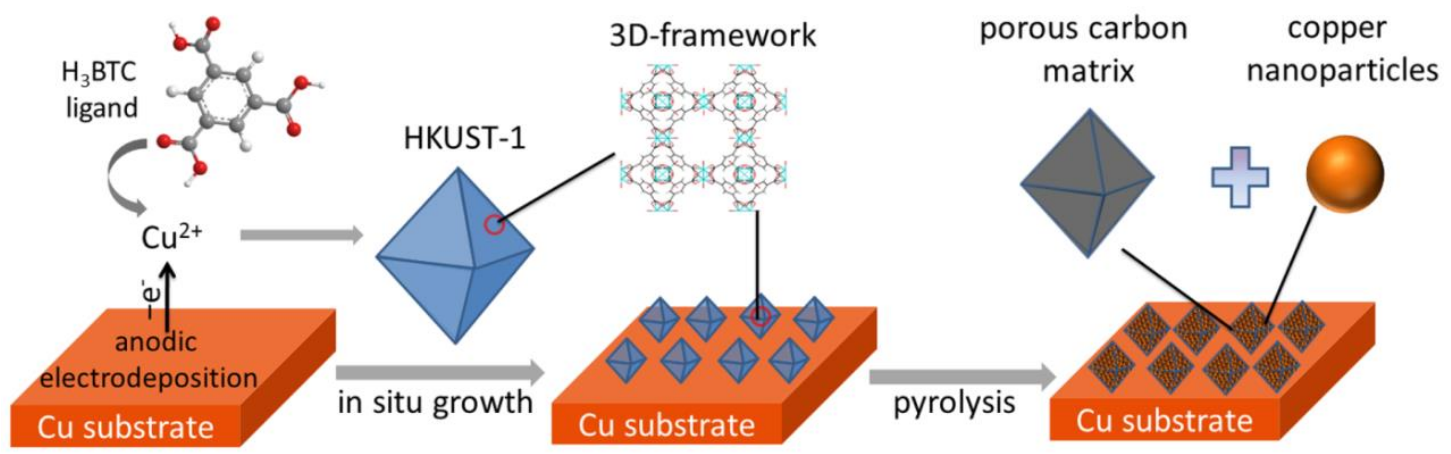

A non-enzymatic glucose sensor based on carbon/Cu composite materials was developed by the in-situ growth and subsequent pyrolysis of metal-organic frameworks (MOFs) on Cu foam. After pyrolysis, the $\mathrm{Cu}$ nanoparticles are uniformly embedded in the carbon matrix, attached on the carbon layer closely. The resulting $\mathrm{Cu} @$ porous carbon matrix electrode displays ultrahigh sensitivity $\left(10.1 \mathrm{~mA} \mathrm{~cm}^{-2} \mathrm{mM}^{-1}\right)$, low detection limit $(<1 \mu \mathrm{M})$, short response time (less than $2 \mathrm{~s}$ ) and good stability, indicating that the developed electrode is a promising candidate material for glucose sensors. 


\title{
Highlights
}

HKUST-1 (Cu-BTC) was directly grown on different copper substrates by anodic electrodeposition.

$\mathrm{Cu}$ nanoparticles embedded in the porous carbon matrix $(\mathrm{Cu} @$ porous carbon material) were successfully fabricated on the $\mathrm{Cu}$ foam without any binder.

The as-prepared $\mathrm{Cu} @$ porous carbon matrix electrode displays ultrahigh sensitivity, low detection limit, short response time and long stability for glucose sensors.

\begin{abstract}
A non-enzymatic glucose sensor based on carbon/Cu composite materials was developed by the in-situ growth and subsequent pyrolysis of metal-organic frameworks (MOFs) on Cu foam. After pyrolysis, SEM, HRTEM and STEM-EELS were employed to clarify the hierarchical $\mathrm{Cu} @$ porous carbon electrode. It is found that the $\mathrm{Cu}$ nanoparticles are uniformly embedded in the carbon matrix, attached on the carbon layer closely. The electrocatalytic activity of the $\mathrm{Cu} @$ porous carbon matrix electrode for glucose sensing was explored by cyclic voltammetry (CV) and chronoamperometry. The resulting $\mathrm{Cu} @$ porous carbon matrix electrode displays ultrahigh sensitivity $\left(10.1 \mathrm{~mA} \mathrm{~cm}^{-2} \mathrm{mM}^{-1}\right)$, low detection limit $(<1 \mu \mathrm{M})$, short response time (less than $2 \mathrm{~s}$ ) and good stability, indicating that the developed electrode is a promising candidate material for glucose sensors.
\end{abstract}

Keywords: metal-organic frameworks, electrodeposition, pyrolysis, carbon-metal composite materials, glucose sensors, ultrasensitive.

\section{Introduction}

Diabetes has become one of the biggest health problems in the world with more than 370 million people affected. ${ }^{1}$ Currently, glucose sensors constitute $85 \%$ of the market share of all biosensor products for detecting diabetes. As more and more people are affected by diabetes, a safe, efficient and noninvasive ultra-sensitive glucose monitoring biosensor is a way to improve patient's adherence and health. Therefore, the development of better and cheaper 
glucose sensors has drawn a lot of attention..$^{2-4}$ Because traditional enzyme-based biosensors are easily affected by temperature, $\mathrm{pH}$ and humidity, glucose sensors based on transition metals (Pt, Au, Ag, $\mathrm{Cu}, \mathrm{Ni}, \mathrm{Fe}, \mathrm{Co}, \mathrm{Mn}$, etc.) as well as their oxides and sulfides in alkaline solutions have been extensively explored as promising candidates for next-generation glucose sensors. ${ }^{5-12}$ Among these materials, $\mathrm{Cu}($ or $\mathrm{CuO})$ is an interesting material for glucose sensor due to the fact that it is inexpensive, non-toxic and environmentally stable. More importantly, the electrochemical glucose oxidation shows fast kinetics on $\mathrm{Cu}($ or $\mathrm{CuO}){ }^{13,14}$

It is well known that the electrocatalytic active surface area plays a critical role in enzymeless analysis. In order to increase the electrocatalytic active surface area, encouraging results have been shown by $\mathrm{Cu}$ nanomaterials (nanoparticles, nanocluster, nanobelts, nanocubes, etc.) for glucose sensors recently. ${ }^{15-19}$ Moreover, in order to avoid the aggregation of nanomaterials and enhance the catalytic activity of $\mathrm{Cu}$ materials, great efforts have been made to combine copper or copper oxides with carbon-based nanomaterials such as carbon nanotubes and graphene. For example, Ding et al. synthesized copper nanoparticles (NPs) decorated nitrogen-doped graphene $(\mathrm{Cu}-\mathrm{N}-\mathrm{G})$ by thermal treatment. Compared with pure $\mathrm{Cu}$ NPs, the $\mathrm{Cu}-\mathrm{N}-\mathrm{G}$ showed enhanced electrocatalytic activity for the glucose oxidation (e.g. the oxidation peak current increased a lot). ${ }^{20}$ Nevertheless, in the typical fabrication process of glucose sensor, the polymer binders such as Nafion, polyvinylidene fluoride (PVDF) or chitosan are used to immobilize active materials. These binders have been shown to increase the electrical resistance, hinder the electrolyte diffusion and decrease the effective active surface area. ${ }^{21-23}$ Thus, plenty of researchers focus on in-situ synthesis of nanostructured $\mathrm{Cu}$ directly on the substrate. For instance, Li et al. successfully prepared free-standing porous $\mathrm{CuO}$ nanowire electrodes on a $\mathrm{Cu}$ foil. The in-situ engineered electrodes show higher sensitivity than "reconstituted" electrodes (electroactive materials that are pasted on an electrode with the addition of a binder). ${ }^{13}$ Furthermore, Zhang et al. used $\mathrm{Cu}$ foam as the precursor for in-situ growth of $\mathrm{CuO}$ nanowires by anodic electrodeposition. ${ }^{24}$ However, the 
preparation of electrodes based on binder-free carbon/Cu composite materials remains challenging.

Metal-organic frameworks (MOFs) are highly porous coordination polymers formed by combining organic linkers and metal ions. Due to their unique structures, nano-scale cavities and open channels, MOFs are considered as promising candidates for synthesizing porous carbon materials and nano-sized metal particles. ${ }^{25-31}$ For example, Song et al. produced 3D anthill-like Cu@carbon nanocomposites successfully by pyrolysis of HKUST-1. The resultant materials shown good catalytic performance towards the oxidation of glucose with a wide range (up to $8 \mathrm{mM}$ ) and low detection limit $(29.8 \mu \mathrm{M}){ }^{28}$ However, complex steps for immobilization of catalyst and polymer binder were still involved. In order to prepare binderfree electrode, multi-step hydrothermal or solvothermal are normally used in traditionally methods, which are both time and resource consuming. ${ }^{32-34}$ Very recently, a new method (patented by BASF) proposed the electrochemical synthesis of MOFs, avoiding the use of salts and saving synthesis time. ${ }^{35}$ Besides, Ameloot et al. reported that densely packed crystalline $\mathrm{Cu}$-based MOF layers could be synthesized on pure copper electrodes by anodic electroprecipitation. ${ }^{36}$ Furthermore, the mechanism of the electrochemical nucleation and growth of HKUST-1 layers have been proposed by our group. ${ }^{37}$

Taking the above considerations into account, we propose a facile method to prepare binder-free electrodes based on carbon/Cu composite materials (Figure 1). Firstly, the archetypal MOF HKUST-1 (Cu-BTC) was directly grown on copper foam by anodic electroprecipitation. After pyrolysis, the $\mathrm{Cu}$ nanoparticles embedded in the porous carbon matrix (Cu@porous carbon material) were successfully fabricated on the $\mathrm{Cu}$ foam. The resulting $\mathrm{Cu} @$ porous carbon matrix electrode was tested as a non-enzymatic electrochemical glucose sensor electrode. The $\mathrm{Cu} @$ porous carbon matrix electrode displayed much better electrochemical catalytic performance towards glucose than $\mathrm{Cu}$ foam and flat copper electrodes. 


\section{Results and discussions}

HKUST-1 was successfully deposited on the copper foam substrate, as shown by the XRD pattern of materials scratched from the substrate (Figure S1). The characteristic peaks of $\mathrm{Cu}$ BTC framework at $2 \theta \approx 9.5^{\circ}, 11.5^{\circ}$ and $13.4^{\circ}$ can be clearly identified, which agree well with previous literature. ${ }^{38}$ Furthermore, HKUST-1 can be deposited on different copper substrates such as plate (Figure 2a), wire (Figure 2b) and foam (Figure 2c). The HKUST-1 grows conformably on the surface of the different copper substrates. This advantage can meet the need of commercial electronic devices. At higher magnification, the typical octahedral morphology of HKUST-1 can be observed (inset of Figure 2c). The crystal sizes range from $2 \mu \mathrm{m}$ to $8 \mu \mathrm{m}$. The result of EDS is illustrated in Figure. S2, confirming the existence of C, $\mathrm{O}$ and $\mathrm{Cu}$ (from HKUST-1) and Pt (from Pt sputtered for SEM imaging). After pyrolysis, the "octahedral unit" remains while the pyrolized MOF still covers the surface of the copper foam (Figure 3). The pyrolytic carbon is expected to act as an electron pathway between the copper nanoparticles and the copper substrate. According to thermogravimetric analysis (TGA) (Figure S3), there are three main weight loss events during pyrolysis. Events A and B probably correspond to the loss of guest molecules of ethanol (b.p. $=78^{\circ} \mathrm{C}$ ) and DMF (b.p. $=$ $153{ }^{\circ} \mathrm{C}$ ), respectively. After that, there is a plateau (event $\mathrm{C}$ ) from $210{ }^{\circ} \mathrm{C}$ to $250{ }^{\circ} \mathrm{C}$, indicating that the framework of HKUST-1 is stable up to $250{ }^{\circ} \mathrm{C}$. Event D starts from $250{ }^{\circ} \mathrm{C}$ and is attributed to the thermal decomposition of the linker molecules. After the thermal decomposition, copper particles can be found dispersed on the surface. Most copper particles are below $300 \mathrm{~nm}$ (Figure 3c and 3d). However, there are some large $\mathrm{Cu}$ particles on the surface of the porous carbon matrix. These particles probably arise from outer surface decomposition of MOF units, especially for the overlap of MOF units as shown in Figure 2c. This phenomenon has been observed before by Song et al. as well. ${ }^{28}$ The EDS measurements (Figure S4) confirm three elements: $\mathrm{C}$ from the carbon matrix, $\mathrm{Cu}$ from nanoparticles and $\mathrm{O}$ from the $\mathrm{CuO}$ thin layer (oxidized in the air), respectively. These results are in good 
agreement with the XRD measurement results. As shown in Figure S5, three characteristic peaks for $\mathrm{Cu}$ were observed at $2 \theta=43.3^{\circ}, 50.4^{\circ}$ and $74.2^{\circ}$, corresponding to Miller indices (111), (200) and (220), respectively. Moreover, a small peak at $2 \theta=36.8^{\circ}$ can be clearly observed, which corresponds to (111) reflection peak of cubic $\mathrm{CuO}$ phase. ${ }^{39,40}$ In this work, copper foam is used as both substrate and copper source. In addition, the photograph of the $\mathrm{Cu}$ foam, HKUST-1-covered and Cu@porous carbon matrix electrodes (Figure S6a) show that the $\mathrm{Cu} @$ porous carbon matrix is in close contact with the $\mathrm{Cu}$ foam. In this work, copper foam is used as both substrate and copper source. The 3D structure of the copper foam provides high surface area, which will increase the sensitivity. Moreover, copper foam shown stronger adhesive for $\mathrm{Cu} @$ porous carbon materials compared with copper plate substrate as displayed in Fig. S6 (a) and (b).

To further explore the structure of single nanoparticles, TEM and STEM-EELS mappings have been conducted. As shown in Figure 4 (a), the nanoparticles are supported by carbon sheets. HRTEM analysis and corresponding reduced FFT (fast Fourier transform) spectra (Figure $\mathbf{4 b}, \mathbf{4 c}$ and $\mathbf{4 d}$ ) show that the outer shell of nanoparticles are cubic $\mathrm{CuO}$ phase, [FM3$\mathrm{M}]$-Space group 225, with lattice parameters of $\mathrm{a}=0.4245 \mathrm{~nm}$, and $\alpha=90^{\circ}$ as visualized along the [112] direction, which perfectly agree with the XRD observations (Figure S5). The RGB composition of IFFT (Inverse fast Fourier transform) from $\mathrm{CuO}$ further confirms the HRTEM analysis (Figure 4e). To figure out the chemical composition of $\mathrm{Cu} @$ porous carbon matrix materials, STEM-EELS has been conducted (Figure 5). The general view and magnified details of the HAADF-STEM images are displayed in Figure 5, which also show that the nanoparticles are supported by carbon sheets. The geometrical shape of the nanoparticles is spherical. Moreover, the relative compositions of $\mathrm{Cu}, \mathrm{O}$ and $\mathrm{C}$ elements of these nanoparticles have been mapped by means of EELS analysis using Hartree-Slater model for signal quantification and power law for background removal. ${ }^{41}$ Clearly, the nanoparticle is embedded in the carbon layer. Around the outer shell of the nanoparticles, there is a thin 
layer with a relatively high $\mathrm{O}$ concentration, which is probably due to the oxidation of the $\mathrm{Cu}$ nanoparticles in air. ${ }^{42}$ In addition, $\mathrm{Cu}$ dominates the main region of the nanoparticles. These results are in good agreement with EDS (Figure S4), TEM (Figure 4) and XRD observations (Figure S5). After glucose sensor performance tests, the structure and chemical compositions of the $\mathrm{Cu} @$ porous carbon matrix materials were analyzed again by TEM and STEM-EELS composition maps extracted from the obtained spectrum images (SIs). It was found that after the performance test, the nanoparticles were still attached to the carbon layer (Figure 6a). After the tests, the structure of the nanoparticles changed to urchin-like particles, which is probably caused by the electrochemical oxidation of $\mathrm{Cu}$ into $\mathrm{CuO}$. A similar change has been observed for the transformation of $\mathrm{Cu}_{2} \mathrm{O}$ into $\mathrm{CuO}$ nanostructures. ${ }^{43}$ However, the hierarchical structure of the nanoparticles embedded in the carbon matrix units remains unchanged (Figure S7a). The HRTEM and corresponding reduced FFT spectra (Figure 6b, 6c and 6d) indicate that the nanoparticle crystallizes in the form of a cubic $\mathrm{CuO}$ phase ([FM3$\mathrm{M}]$-Space group 225, with lattice parameters of $\mathrm{a}=0.4245 \mathrm{~nm}$, and $\alpha=90^{\circ}$ as visualized along the [011] direction). Furthermore, the relative $\mathrm{O}$ content of the particles increased significantly due to the presence of cubic $\mathrm{CuO}$ phase after the sensor test (Figure 6e), which is confirmed by EDS results (Figure S6b). It is worth noting from the relative $\mathrm{C}$ content of the nanoparticles that each particle is covered by a thin carbon layer and connected by a carbon layer to each other. This unique structure might be the reason for the transport of charge and the protection of the nanoparticles from aggregation and degradation during glucose oxidation. Combining XRD patterns (Figure S5), TEM observations (Figure 4, 5 and 6) and the electrochemical information (as shown in Figures 7 and 8) of $\mathrm{Cu} @$ porous carbon matrix materials for the glucose sensor, the possible electro-oxidation mechanism of glucose on the $\mathrm{Cu} @$ porous carbon matrix surface in an alkaline solution can be assumed as follows: ${ }^{44,45}$

$\mathrm{Cu}+2 \mathrm{OH}^{-}-2 \mathrm{e}^{-} \rightleftharpoons \mathrm{Cu}(\mathrm{OH})_{2}$ 
$\mathrm{Cu}(\mathrm{OH})_{2}+\mathrm{OH}^{-} \rightleftharpoons \mathrm{CuOOH}+\mathrm{H}_{2} \mathrm{O}+\mathrm{e}^{-}$

$\mathrm{CuOOH}+\mathrm{e}^{-}+$glucose $\rightarrow \mathrm{CuO}+\mathrm{OH}^{-}+$gluconic acid

$\mathrm{CuO}+\mathrm{OH}^{-} \rightleftharpoons \mathrm{CuOOH}+\mathrm{e}^{-}$

The reactions (1) and (2) occur in activated process before test. ${ }^{46,47}$ After addition of glucose, the oxidative $\mathrm{Cu}(\mathrm{III})$ could catalyze glucose oxidation to generate gluconolactone and then gluconolactone is further oxidized to glucose acid. The reaction catalyzed by $\mathrm{Cu} @$ porous carbon matrix electrode was assisted by the $\mathrm{Cu}(\mathrm{II}) / \mathrm{Cu}(\mathrm{III})$ redox couple.

The $\mathrm{CV}$ curves of the $\mathrm{Cu} @$ porous carbon matrix electrode in $0.1 \mathrm{M} \mathrm{NaOH}$ with different concentrations of glucose at a scan rate of $50 \mathrm{mV} \mathrm{s}^{-1}$ is shown in Figure 7a. In the absence of glucose (curve A), there is no obvious oxidation peak. When glucose was added to the $0.1 \mathrm{M}$ $\mathrm{NaOH}$ solution, a clear increase of the oxidative peak current was observed in the potential range between $+0.4 \mathrm{~V}$ and $+0.7 \mathrm{~V}(v s . \mathrm{Hg} / \mathrm{HgO})$, corresponding to the irreversible oxidation of glucose. The optimal detection potential was determined from the amperometric responses of the $\mathrm{Cu} @$ porous carbon matrix electrode at different potentials from +0.45 to $+0.65 \mathrm{~V}$ with the addition of $1 \mathrm{mM}$ glucose (Figure 7b). The $\mathrm{Cu} @$ porous carbon matrix electrode shows only a slightly lower current response at $+0.55 \mathrm{~V}$ than $+0.6 \mathrm{~V}$. However, at higher potentials the influence of interferences and polarization of the oxygen evolution are larger. Therefore, the potential is subsequently fixed at $+0.55 \mathrm{~V}$ for amperometric $i$ - $t$ tests. The amperometric responses of the $\mathrm{Cu}$ plate, $\mathrm{Cu}$ foam, $\mathrm{AO}-\mathrm{Cu}$ foam and $\mathrm{Cu} @$ porous carbon matrix electrode to $1 \mathrm{mM}$ glucose at $+0.55 \mathrm{~V}$ in $0.1 \mathrm{M} \mathrm{NaOH}$ are shown in Figure 7c. The copper foam shows a $100 \%$ increase in current compared to the copper plate due to its larger surface area. After anodic oxidation, the AO-Cu foam electrode showed 55\% higher current response than copper foam due to surface structure change of copper foam as exhibited in Figure. S8. The 3D structure skeleton of $\mathrm{Cu}$ foam can be remaining well after anodic oxidation process (Figure. S8a and Figure. S8d). However, the smooth surface of $\mathrm{Cu}$ foam was changed to porous nest structure, which probably caused by oxygen evolution bubble during anodic oxidation 
process, ${ }^{48-50}$ and the diameter of these pores is around $3 \mu \mathrm{m}$ as displayed in Figure. S8(e). At high magnification, it is can be seen that porous nanostructure constructed the nest structure. Then the copper foam was further decorated by $\mathrm{Cu} @$ porous carbon matrix, the resulting electrode shown even $20 \%$ higher current response for $1 \mathrm{mM}$ glucose than $\mathrm{AO}-\mathrm{Cu}$ foam electrode.

Figure 8a displays an amperometric $i$ - $t$ test measured in $0.1 \mathrm{M} \mathrm{NaOH}$ at $+0.55 \mathrm{~V}$ under stepwise addition of glucose. When the current was stable, different concentrations of glucose solutions were successively injected into the solution under stirring, which induced an increase in the current within $2 \mathrm{~s}$. The low-concentration part is magnified and shown in the inset above the amperometric $i$ - $t$ curve. Another inset is the amperometric response of the $\mathrm{Cu} @$ porous carbon matrix electrode to the addition of $1 \mu \mathrm{M}$ and $2.5 \mu \mathrm{M}$ glucose solutions. An increase of current can be clearly identified even for $1 \mu \mathrm{M}$ glucose. Moreover, as shown in Figure $\mathrm{S} 9$, the $\mathrm{AO}-\mathrm{Cu}$ foam electrode and $\mathrm{Cu} @$ porous carbon matrix decorated copper foam show highest current response for $10 \mu \mathrm{M}$ glucose than bare copper foam or copper plate. Besides, there is no obviously current increase for the bare copper foam or copper plate electrode with the addition of $1 \mu \mathrm{M}$ of glucose. The calibration curves based on the results of the amperometric $i$ - $t$ test is presented in Figure $\mathbf{8 b}$. The current $(i)$ is correlated with the glucose concentration (c) in the range of $1 \mu \mathrm{M}-6000 \mu \mathrm{M}$ with a correlation coefficient of 0.9998 using the following equation: ${ }^{45}$

$$
i=\frac{12.1 \mathrm{c}}{928.9+c}
$$

Between $1 \mu \mathrm{M}$ and $300 \mu \mathrm{M}$ glucose, the response is linear $\left(R^{2}=0.9947\right)$ as shown in the inset of Figure 8b. In this concentration range (linear part), the sensitivity is $10.1 \mathrm{~mA} \mathrm{~cm}-2 \mathrm{mM}^{-1}$ based on projected geometrical electrode area. The limit of detection is estimated to be 0.6 $\mu \mathrm{M}$ at a signal-to-noise ratio of 3. Cu@ porous carbon matrix electrode showed a comparable 
sensing performance to previous reports (Table S1), especially showing an ultrahigh sensitivity as shown in Figure 9.

As there are various oxidizable species present in human body fluids, such as uric acid (UA), ascorbic acid (AA), sucrose, fructose, the ability to discriminate these interferences is an important factor for glucose sensors. Under stepwise addition of the same amount $(0.1$ $\mathrm{mM}$ ) of glucose, UA, AA, sucrose, fructose, the interferences showed obvious current responses as shown in curve A (Figure 10a). Considering in human blood the concentration of these interferences are much smaller $(<1 / 30)$ than the concentration of glucose, ${ }^{51-54}$ generally speaking, the ratio of glucose concentration and interference concentration are 1:10 or at physiological concentration level (around 1:30) in selectivity test. ${ }^{55-61}$ When the concentration of the interferences was decreased from $0.1 \mathrm{mM}$ to $0.01 \mathrm{mM}$ (curve B, Figure 10a) or physiological concentration level (curve $C$ and, Figure 10a), no current response can be observed for species other than glucose. These results suggest that the $\mathrm{Cu} @$ porous carbon matrix electrode shown reliable anti-interference property at physiological concentration level. Furthermore, the stability of the $\mathrm{Cu} @$ porous carbon matrix electrode was investigated by recording the continuous or intermittent amperometric responses to $0.1 \mathrm{mM}$ glucose. The longtime current response of the $\mathrm{Cu} @$ porous carbon matrix electrode indicates that around 89\% can be retained during a period of $1800 \mathrm{~s}$ (Figure 10b). Furthermore, after storage at room temperature in ambient atmosphere for 25 days, the sensitivity of the electrode decreased only slightly compared with its initial response as shown in the inset of Figure 10b.

\section{Conclusions}

In summary, HKUST-1 can be easily synthesized on the different kinds of copper substrates. After pyrolysis, carbon-Cu composite materials can be grown in-situ on the $\mathrm{Cu}$ foam. The resulting electrode shows high sensitivity, low detection limit and good stability for the non-enzymatic detection of glucose. The excellent electrochemical performance of the $\mathrm{Cu} @$ porous carbon matrix electrode can be attributed to the multidimensional hierarchical 
structure of the electrode and the synergistic effect between $\mathrm{Cu}$ and carbon. These results indicate that the $\mathrm{Cu} @$ porous carbon matrix electrode could be a promising candidate for the construction of non-enzymatic glucose sensors, especially for saliva-based glucose sensors due to the very high sensitivity.

\section{Experimental section}

Electrodeposited MOF: All reagents were of analytical purity without further purification. Three kinds of copper substrates were used to prepared MOF-covered electrodes: copper plate (thickness: $1 \mathrm{~mm}, 99 \%$ purity, Testas, Belgium), copper wire (diameter: $1.5 \mathrm{~mm}$ ) and copper foam (thickness: $1 \mathrm{~mm}$, pore density: 90 ppi, $\mathrm{Cu}>99.5 \%$, Changsha LYRUN New Material China Co., Ltd.). Before electrodeposition, the copper substrate was carefully cleaned with dilute hydrochloric acid, acetone and ultrapure water several times, respectively. Unless stated otherwise, the anodic MOF deposition was performed on different kinds of copper substrates under the same conditions. Copper plates were used as the cathode, and different copper substrates were used as the anode. The electrodeposition was performed in a solution containing $1 \mathrm{~g}$ 1,3,5-benzenetricarboxylic acid $\left(\mathrm{H}_{3} \mathrm{BTC}\right)$ and $0.5 \mathrm{~g}$ methyltributylammonium methyl sulfate (MTBS) per $100 \mathrm{~mL}$ solvent $\left(67 \mathrm{~mL}\right.$ ethanol and $33 \mathrm{~mL}$ Milli-Q ${ }^{\circledR}$ water). By applying a current density of $4 \mathrm{~mA} \mathrm{~cm}^{-2}$ at room temperature until the total passed charge reached $36 \mathrm{C} \mathrm{cm}^{-2}$, MOFs were grown on the copper substrates. The current densities were determined by projected geometric area. After MOF growth, the MOF-covered electrode was washed with ethanol and dimethylformamide (DMF) to remove excess ligand and MTBS.

Preparation of $\mathrm{Cu} @$ porous carbon matrix electrode: The MOF-covered copper foam electrodes were pyrolized at $850{ }^{\circ} \mathrm{C}$ in flowing argon gas $(99.998 \%)$ with a flow rate of 300 $\mathrm{cm}^{3} \mathrm{~min}^{-1}$. The temperature inside the furnace was gradually increased from room temperature to the target temperature at a heating rate of $3{ }^{\circ} \mathrm{C} \mathrm{min}^{-1}$. After the target temperature was reached, the MOF-covered copper foam electrode was annealed for $8 \mathrm{~h}$ and then cooled down to room temperature at a rate of $5{ }^{\circ} \mathrm{C} \min ^{-1}$. The as-prepared electrode is 
denoted as $\mathrm{Cu} @$ porous carbon matrix electrode. For comparison, $\mathrm{Cu}$ foam was directly anodic oxidation without $\mathrm{H}_{3} \mathrm{BTC}$ at the same current density and total passed charge, which named as $\mathrm{AO}-\mathrm{Cu}$ foam. Besides, a copper plate and a copper foam were used for comparative experimental as well.

Material characterizations: X-ray diffraction (XRD) data of the samples were collected on a Bruker AXS D8 diffractometer using $\mathrm{Cu} \mathrm{K}_{\alpha}$ radiation (wavenumber $\lambda=0.15405 \mathrm{~nm}$ ) and $\mathrm{Ni}$ filter from $5^{\circ}$ to $50^{\circ}$ in $2 \theta$ with a step of $0.02^{\circ}$ ( $2 \mathrm{~s}$ per step). TGA was performed in an argon atmosphere on a thermogravimetric analyzer (AutoTGA 2950HR V5.4A, TA Instruments) using platinum pans at a heating rate of $3{ }^{\circ} \mathrm{C} \min ^{-1}$. For the XRD and TGA tests, the sample was scratched off from the copper substrate. The morphology of the samples and energy dispersive spectroscopy (EDS) were observed on a FEI/Philips XL30 FEG microscope (SEM). In order to improve the electronic conductivity of the MOF samples, a $5 \mathrm{~nm}$ layer of Pt was sputtered on top of the samples. The onset temperature of the weight loss in the TGA was used as the decomposition temperature $\left(T_{\mathrm{d}}\right)$. High resolution transmission electron microscopy (HRTEM) and scanning transmission electron microscopy (STEM) images were obtained by using an FEI Tecnai F20 field emission gun microscope operated at $200 \mathrm{kV}$ with a point-to-point resolution of $0.19 \mathrm{~nm}$, which is equipped with high angle annular dark field (HAADF) and electron energy loss spectroscopy (EELS) detectors The obtained images and spectra were analyzed by means of Gatan Digital Micrograph software.

Electrochemical characterizations: The electrochemical performance of the samples was characterized by chronoamperometry $(i-t)$ and cyclic voltammetry $(\mathrm{CV})$ techniques with an Autolab electrochemical workstation at room temperature in a three-electrode system. The as-prepared electrode with an immersed area of $1 \times 1 \mathrm{~cm}^{2}$, platinum gauze and an $\mathrm{Hg} / \mathrm{HgO}$ electrode were used as the working electrode, the counter electrode and the reference electrode, respectively. For comparative experimental, all the electrodes are fixed at same 
immersed area $\left(1 \times 1 \mathrm{~cm}^{2}\right)$. In this paper, all the current densities were normalized by the projected geometrical electrode area. The working electrode was used after being activated for several cycles of cyclic voltammetry form 0 to $0.65 \mathrm{~V}$ at a scan rate of $50 \mathrm{mV} \mathrm{s}^{-1}$ until $\mathrm{CV}$ curves are stable. The supporting electrolyte in all electrochemical experiments is $0.1 \mathrm{M}$ $\mathrm{NaOH}$.

\section{Acknowledgements}

X. Zhang is grateful to China Scholarship Council. Financial support from China Fund KU Leuven (ISP/13/02SJT) is acknowledged. J. Luo acknowledges the Research Foundation Flanders (FWO) for a FWO Postdoctoral Fellowship (12F5514N), a Research Grant $(1529816 \mathrm{~N})$ and a travel grant (V410316N) for a Visiting Professorship at the Technical University of Denmark. C. L. Xu thanks the National Natural Science Foundation of China (No. 21673105) and the Fundamental Research Funds for the Central Universities (lzujbky2016-k09). JA, PYT and JRM acknowledge funding from Generalitat de Catalunya 2014 SGR 1638 and the Spanish MINECO coordinated projects between IREC and ICN2 TNT-FUELS and e-TNT (MAT2014-59961-C2-2-R). ICN2 acknowledges support from the Severo Ochoa Program (MINECO, Grant SEV-2013-0295). Part of the present work has been performed in the framework of Universitat Autonoma de Barcelona Materials Science Ph.D. program. Funding from "Minjiang Scholar" Program and key project (No. JZ160480) of Department of Education, Fujian Province, China is also acknowledged.

Received: ((will be filled in by the editorial staff))

Revised: ((will be filled in by the editorial staff)) Published online: ((will be filled in by the editorial staff)) 


\section{References}

1. Fisher, K.; Griffith, L.; Gruneir, A.; Panjwani, D.; Gandhi, S.; Sheng, L.; Gafni, A.; Chris, P.; Markle-Reid, M.; Ploeg, J., Comorbidity and its relationship with health service use and cost in community-living older adults with diabetes: A population-based study in Ontario, Canada. Diabetes Research and Clinical Practice 2016, 122, 113-123.

2. Wang, G.; He, X.; Wang, L.; Gu, A.; Huang, Y.; Fang, B.; Geng, B.; Zhang, X., Nonenzymatic electrochemical sensing of glucose. Microchimica Acta 2012, 180 (3-4), 161-186.

3. Wang, J., Electrochemical glucose biosensors. Chemical Reviews 2008, 108 (2), 814-825.

4. Zaidi, S. A.; Shin, J. H., Recent developments in nanostructure based electrochemical glucose sensors. Talanta 2016, 149, 30-42.

5. Feng, D.; Wang, F.; Chen, Z., Electrochemical glucose sensor based on one-step construction of gold nanoparticle-chitosan composite film. Sensors and Actuators B: Chemical 2009, 138 (2), 539-544;

6. Guo, C.; Zhang, X.; Huo, H.; Xu, C.; Han, X., $\mathrm{Co}_{3} \mathrm{O}_{4}$ microspheres with free-standing nanofibers for high performance non-enzymatic glucose sensor. The Analyst 2013, 138 (22), 6727-6731.

7. Lu, W.; Qin, X.; Asiri, A. M.; Al-Youbi, A. O.; Sun, X., Ni foam: a novel three-dimensional porous sensing platform for sensitive and selective nonenzymatic glucose detection. The Analyst 2013, 138 (2), 417-420.

8. Qian, L.; Mao, J.; Tian, X.; Yuan, H.; Xiao, D., In situ synthesis of $\mathrm{CuS}$ nanotubes on $\mathrm{Cu}$ electrode for sensitive nonenzymatic glucose sensor. Sensors and Actuators B: Chemical 2013, 176, 952-959.

9. Ren, X.; Meng, X.; Chen, D.; Tang, F.; Jiao, J., Using silver nanoparticle to enhance current response of biosensor. Biosensors \& Bioelectronics 2005, 21 (3), 433-437.

10. Wei, H.; Wang, E., $\mathrm{Fe}_{3} \mathrm{O}_{4}$ magnetic nanoparticles as peroxidase mimetics and their applications in $\mathrm{H}_{2} \mathrm{O}_{2}$ and glucose detection. Analytical Chemistry 2008, 80 (6), 2250-2254.

11. Yuan, J.; Cen, Y.; Kong, X. J.; Wu, S.; Liu, C. L.; Yu, R. Q.; Chu, X., MnO $\mathrm{M}_{2}-\mathrm{Nanasheet}^{-}$ Modified Upconversion Nanosystem for Sensitive Turn-On Fluorescence Detection of $\mathrm{H}_{2} \mathrm{O}_{2}$ and Glucose in Blood. ACS Applied Materials \& Interfaces 2015, 7 (19), 10548-10555.

12. Zhai, D.; Liu, B.; Shi, Y.; Pan, L.; Wang, Y.; Li, W.; Zhang, R.; Yu, G., Highly sensitive glucose sensor based on Pt nanoparticle/polyaniline hydrogel heterostructures. ACS Nano 2013, 7 (4), 3540-3546.

13. Huang, J.; Zhu, Y.; Yang, X.; Chen, W.; Zhou, Y.; Li, C., Flexible 3D porous CuO nanowire arrays for enzymeless glucose sensing: in situ engineered versus ex situ piled. Nanoscale 2015, 7 (2), 559-569.

14. Meher, S. K.; Rao, G. R., Archetypal sandwich-structured $\mathrm{CuO}$ for high performance nonenzymatic sensing of glucose. Nanoscale 2013, 5 (5), 2089-2099.

15. Huang, T. K.; Lin, K. W.; Tung, S. P.; Cheng, T. M.; Chang, I. C.; Hsieh, Y. Z.; Lee, C. Y.; Chiu, H. T., Glucose sensing by electrochemically grown copper nanobelt electrode. Journal of Electroanalytical Chemistry 2009, 636 (1-2), 123-127.

16. Kang, X.; Mai, Z.; Zou, X.; Cai, P.; Mo, J., A sensitive nonenzymatic glucose sensor in alkaline media with a copper nanocluster/multiwall carbon nanotube-modified glassy carbon electrode. Analytical Biochemistry 2007, 363 (1), 143-150.

17. Xu, Q.; Zhao, Y.; Xu, J. Z.; Zhu, J. J., Preparation of functionalized copper nanoparticles and fabrication of a glucose sensor. Sensors and Actuators B: Chemical 2006, 114 (1), 379386.

18. Yang, J.; Zhang, W. D.; Gunasekaran, S., An amperometric non-enzymatic glucose sensor by electrodepositing copper nanocubes onto vertically well-aligned multi-walled carbon nanotube arrays. Biosensors \& bioelectronics 2010, 26 (1), 279-284.

19. Zhang, L.; Zhang, J.; Yang, C.; Zhao, G.; Mu, J.; Wang, Y., Freestanding $\mathrm{Cu}$ nanowire arrays on $\mathrm{Ti} / \mathrm{Cr} / \mathrm{Si}$ substrate as tough nonenzymatic glucose sensors. $R S C A d v$. 2015, 5 (101), 
82998-83003.

20. Jiang, D.; Liu, Q.; Wang, K.; Qian, J.; Dong, X.; Yang, Z.; Du, X.; Qiu, B., Enhanced nonenzymatic glucose sensing based on copper nanoparticles decorated nitrogen-doped graphene. Biosensors \& Bioelectronics 2014, 54, 273-278.

21. Ahmad, R.; Tripathy, N.; Jung, D. U.; Hahn, Y. B., Highly sensitive hydrazine chemical sensor based on $\mathrm{ZnO}$ nanorods field-effect transistor. Chemical Communications 2014, 50 (15), 1890-1893.

22. Jia, W.; Guo, M.; Zheng, Z.; Yu, T.; Wang, Y.; Rodriguez, E. G.; Lei, Y., Vertically Aligned $\mathrm{CuO}$ Nanowires Based Electrode for Amperometric Detection of Hydrogen Peroxide. Electroanalysis 2008, 20 (19), 2153-2157.

23. Sun, S.; Zhang, X.; Sun, Y.; Yang, S.; Song, X.; Yang, Z., Facile water-assisted synthesis of cupric oxide nanourchins and their application as nonenzymatic glucose biosensor. ACS Applied Materials \& Interfaces 2013, 5 (10), 4429-4437.

24. Li, Z.; Chen, Y.; Xin, Y.; Zhang, Z., Sensitive electrochemical nonenzymatic glucose sensing based on anodized $\mathrm{CuO}$ nanowires on three-dimensional porous copper foam. Scientific Reports 2015, 5, 16115-16123.

25. Bak, W.; Kim, H. S.; Chun, H.; Yoo, W. C., Facile synthesis of metal/metal oxide nanoparticles inside a nanoporous carbon matrix (M/MO@C) through the morphologypreserved transformation of metal-organic framework. Chemical Communications 2015, 51 (33), 7238-7241.

26. Liu, J.; Wang, H.; Wu, C.; Zhao, Q.; Wang, X.; Yi, L., Preparation and characterization of nanoporous carbon-supported platinum as anode electrocatalyst for direct borohydride fuel cell. International Journal of Hydrogen Energy 2014, 39 (12), 6729-6736.

27. Pandiaraj, S.; Aiyappa, H. B.; Banerjee, R.; Kurungot, S., Post modification of MOF derived carbon via $\mathrm{g}-\mathrm{C}_{3} \mathrm{~N}_{4}$ entrapment for an efficient metal-free oxygen reduction reaction. Chemical Communications 2014, 50 (25), 3363-3366.

28. Wei, C.; Li, X.; Xu, F.; Tan, H.; Li, Z.; Sun, L.; Song, Y., Metal organic frameworkderived anthill-like $\mathrm{Cu} @$ carbon nanocomposites for nonenzymatic glucose sensor. Analytical Methods 2014, 6 (5),1550-1557.

29. Yue, H.; Shi, Z.; Wang, Q.; Cao, Z.; Dong, H.; Qiao, Y.; Yin, Y.; Yang, S., MOF-derived cobalt-doped $\mathrm{ZnO} @ \mathrm{C}$ composites as a high-performance anode material for lithium-ion batteries. ACS Applied Materials \& I-nterfaces 2014, 6 (19), 17067-17074.

30. Zhang, P.; Sun, F.; Xiang, Z.; Shen, Z.; Yun, J.; Cao, D., ZIF-derived in situ nitrogendoped porous carbons as efficient metal-free electrocatalysts for oxygen reduction reaction. Energy \& Environmental Science 2014, 7 (1), 442-450.

31. Zhang, X.; Luo, J.; Tang, P.; Ye, X.; Peng, X.; Tang, H.; Sun, S. G.; Fransaer, J., A universal strategy for metal oxide anchored and binder-free carbon matrix electrode: A supercapacitor case with superior rate performance and high mass loading. Nano Energy 2017, 31, 311-321.

32. Guo, H.; Zhu, G.; Hewitt, I. J.; Qiu, S., "Twin Copper Source” Growth of Metal- Organic Framework Membrane: $\mathrm{Cu}_{3}(\mathrm{BTC})_{2}$ with High Permeability and Selectivity for Recycling $\mathrm{H}_{2}$. Journal of the American Chemical Society 2009, 131 (5), 1646-1647.

33. Hu, Y.; Dong, X.; Nan, J.; Jin, W.; Ren, X.; Xu, N.; Lee, Y. M., Metal-organic framework membranes fabricated via reactive seeding. Chemical communications 2011, 47 (2), 737-739. 34. Wang, L.; Xie, Y.; Wei, C.; Lu, X.; Li, X.; Song, Y., Hierarchical NiO Superstructures/Foam Ni Electrode Derived from Ni Metal-Organic Framework Flakes on Foam Ni for Glucose Sensing. Electrochimica Acta 2015, 174, 846-852.

35. U. Mueller, H. Putter, M. Hesse, M. Schubert, H. Wessel, J. Huff and M. Guzmann, US Pat. 2007/0227898 A1, 2007.

36. Ameloot, R.; Stappers, L.; Fransaer, J.; Alaerts, L.; Sels, B. F.; De Vos, D. E., Patterned Growth of Metal-Organic Framework Coatings by Electrochemical Synthesis. Chemistry of 
Materials 2009, 21 (13), 2580-2582.

37. Campagnol, N.; Van Assche, T. R. C.; Li, M.; Stappers, L.; Dincă, M.; Denayer, J. F. M.; Binnemans, K.; De Vos, D. E.; Fransaer, J., On the electrochemical deposition of metalorganic frameworks. J. Mater. Chem. A 2016, 4 (10), 3914-3925.

38. Campagnol, N.; Van Assche, T.; Boudewijns, T.; Denayer, J.; Binnemans, K.; De Vos, D.; Fransaer, J., High pressure, high temperature electrochemical synthesis of metal-organic frameworks: films of MIL-100 (Fe) and HKUST-1 in different morphologies. Journal of Materials Chemistry A 2013, 1 (19), 5827-5830.

39. Kim, S. S.; Na, H. G.; Choi, S. W.; Kwak, D. S.; Kim, H. W., Novel growth of CuOfunctionalized, branched $\mathrm{SnO}_{2}$ nanowires and their application to $\mathrm{H}_{2} \mathrm{~S}$ sensors. Journal of Physics D: Applied Physics 2012, 45 (20), 205301-8.

40. Zhang, X.; Wang, L.; Liu, C.; Ding, Y.; Zhang, S.; Zeng, Y.; Liu, Y.; Luo, S., A bambooinspired hierarchical nanoarchitecture of $\mathrm{Ag} / \mathrm{CuO} / \mathrm{TiO}_{2}$ nanotube array for highly photocatalytic degradation of 2,4-dinitrophenol. Journal of Hazardous Materials 2016, 313, 244-252.

41.Verbeeck, J.; Van Aert, S., Model based quantification of EELS spectra. Ultramicroscopy 2004, 101 (2-4), 207-224.

42. Keil, P.; Lützenkirchen - Hecht, D.; Frahm, R.; Hedman, B.; Pianetta, P. In Investigation of Room Temperature Oxidation of $\mathrm{Cu}$ in Air by Yoneda - XAFS, AIP Conference Proceedings, AIP: 2007; 490-492.

43. Sun, S.; Zhang, X.; Sun, Y.; Zhang, J.; Yang, S.; Song, X.; Yang, Z., A facile strategy for the synthesis of hierarchical $\mathrm{CuO}$ nanourchins and their application as non-enzymatic glucose sensors. RSC Advances 2013, 3 (33), 13712-13719.

44. Kong, C.; Tang, L.; Zhang, X.; Sun, S.; Yang, S.; Song, X.; Yang, Z., Templating synthesis of hollow $\mathrm{CuO}$ polyhedron and its application for nonenzymatic glucose detection. Journal of Materials Chemistry A 2014, 2 (20), 7306-7312;

45. Li, K.; Fan, G.; Yang, L.; Li, F., Novel ultrasensitive non-enzymatic glucose sensors based on controlled flower-like $\mathrm{CuO}$ hierarchical films. Sensors and Actuators B: Chemical 2014, 199, 175-182.

46. Le, W. Z.; Liu, Y. Q., Preparation of nano-copper oxide modified glassy carbon electrode by a novel film plating/potential cycling method and its characterization. Sensors and Actuators B: Chemical 2009, 141 (1), 147-153.

47. Xiao, X.; Wang, M.; Li, H.; Pan, Y.; Si, P., Non-enzymatic glucose sensors based on controllable nanoporous gold/copper oxide nanohybrids. Talanta 2014, 125, 366-71.

48. Zhu, X.; Liu, L.; Song, Y.; Jia, H.; Yu, H.; Xiao, X.; Yang, X., Oxygen evolution and porous anodic alumina formation. Materials Letters 2008, 62 (24), 4038-4040.

49. Comisso, N.; Cattarin, S.; Guerriero, P.; Mattarozzi, L.; Musiani, M.; Verlato, E.,

Electrochemical Behaviour of Porous $\mathrm{PbO}_{2}$ Layers Prepared by Oxygen Bubble Templated

Anodic Deposition. Electrochimica Acta 2016, 200, 259-267.

50. Chelliah, N. M.; Saxena, A.; Sharma, K.; Singh, H.; Surappa, M. K., Surface

characterization of nanoporous aluminium oxide films synthesized by single-step DC and AC anodization. Surfaces and Interfaces 2017, 7, 139-145.

51. Zhang, Y.; Su, L.; Manuzzi, D.; de los Monteros, H. V.; Jia, W.; Huo, D.; Hou, C.; Lei, Y., Ultrasensitive and selective non-enzymatic glucose detection using copper nanowires. Biosensors \& Bioelectronics 2012, 31 (1), 426-432.

52. Li, H.; Guo, C. Y.; Xu, C. L., A highly sensitive non-enzymatic glucose sensor based on bimetallic $\mathrm{Cu}-\mathrm{Ag}$ superstructures. Biosensors \& Bioelectronics 2015, 63, 339-346.

53. Xiao, X.; Wang, M.; Li, H.; Pan, Y.; Si, P., Non-enzymatic glucose sensors based on controllable nanoporous gold/copper oxide nanohybrids. Talanta 2014, 125, 366-371. 
54. Zhang, Y.; Liu, Y.; Su, L.; Zhang, Z.; Huo, D.; Hou, C.; Lei, Y., CuO nanowires based sensitive and selective non-enzymatic glucose detection. Sensors and Actuators B: Chemical 2014, 191, 86-93.

55. Zhuang, Z.; Su, X.; Yuan, H.; Sun, Q.; Xiao, D.; Choi, M. M., An improved sensitivity non-enzymatic glucose sensor based on a $\mathrm{CuO}$ nanowire modified $\mathrm{Cu}$ electrode. The Analyst 2008, 133 (1), 126-132.

56. Dhara, K.; Stanley, J.; T, R.; Nair, B. G.; T.G, S. B., Pt-CuO nanoparticles decorated reduced graphene oxide for the fabrication of highly sensitive non-enzymatic disposable glucose sensor. Sensors and Actuators B: Chemical 2014, 195, 197-205.

57. Huo, H.; Zhao, Y.; Xu, C., 3D Ni3S2nanosheet arrays supported on Ni foam for highperformance supercapacitor and non-enzymatic glucose detection. Journal of Materials Chemistry A 2014, 2 (36), 15111-15117.

58. Kung, C.-W.; Cheng, Y.-H.; Ho, K.-C., Single layer of nickel hydroxide nanoparticles covered on a porous $\mathrm{Ni}$ foam and its application for highly sensitive non-enzymatic glucose sensor. Sensors and Actuators B: Chemical 2014, 204, 159-166.

59. Dong, J.; Ren, L.; Zhang, Y.; Cui, X.; Hu, P.; Xu, J., Direct electrodeposition of cable-like $\mathrm{CuO} @ \mathrm{Cu}$ nanowires array for non-enzymatic sensing. Talanta 2015, 132, 719-726.

60. Liu, H.; Wu, X.; Yang, B.; Li, Z.; Lei, L.; Zhang, X., Three-Dimensional Porous NiO Nanosheets Vertically Grown on Graphite Disks for Enhanced Performance Non-enzymatic Glucose Sensor. Electrochimica Acta 2015, 174, 745-752.

61. Zhong, G.-X.; Zhang, W.-X.; Sun, Y.-M.; Wei, Y.-Q.; Lei, Y.; Peng, H.-P.; Liu, A.-L.; Chen, Y.-Z.; Lin, X.-H., A nonenzymatic amperometric glucose sensor based on three dimensional nanostructure gold electrode. Sensors and Actuators B: Chemical 2015, 212, 72 77. 
Author Biographies

Xuan Zhang is pursuing a $\mathrm{PhD}$ degree in the Department of Materials Engineering at $\mathrm{KU}$ Leuven under the supervision of Prof. Jan Fransaer and Dr. Jiangshui Luo in the group of Surface and Interface Engineered Materials. He obtained his BSc and MSc degrees in Physical Chemistry from Lanzhou University. His current research focuses on synthesis and characterizations of carbon-metal oxide composite electrode materials for lithium-ion batteries, supercapacitors and fuel cells.

Prof. Jiangshui Luo works in KU Leuven as a Senior Researcher and Project Leader. From 2008 to 2011, he was a Project Researcher in EWE Research Center for Energy Technology. He was a visiting professor in the group of Professor Qingfeng Li at Technical University of Denmark in 2016. His current research focuses closely on energy materials such as proton conductors with more than 20 SCI-indexed papers. He proposed and demonstrated protic organic ionic plastic crystals (POIPCS) as a new type of proton conductors for fuel cells. He received his bachelor's, master's and PhD degrees from Xiamen University, Dalian Institute of Chemical Physics and KU Leuven, respectively. He was awarded the 2012 Chinese Government Award for Outstanding Self-Financed Student Abroad. In 2013, he was awarded FWO Postdoctoral Fellowship, a national talent program funded by Research Foundation Flanders (FWO) in Belgium. In 2016, he was awarded the title of "Minjiang Scholar Distinguished Professor" by Fujian province, China.

Prof. Jordi Arbiol graduated in Physics at Universitat de Barcelona (UB) in 1997, where he also obtained his $\mathrm{PhD}$ (European Doctorate and PhD Extraordinary Award) in 2001 in the field of transmission electron microscopy (TEM) applied to nanostructured materials. He was Assistant Professor at UB. From 2009 to 2015 he was Group Leader at Institut de Ciència de Materials de Barcelona, ICMAB-CSIC. Since 2013 he is Vice-President of the Spanish Microscopy Society (SME).

Since 2015 he is the leader of the Group of Advanced Electron Nanoscopy at Institut Català de

Nanociència i Nanotecnologia (ICN2), CSIC and The Barcelona Institute of Science and Technology.

He has been awarded with the 2014 EMS Outstanding Paper Award, the EU40 Materials Prize 2014 (E-MRS), listed in the Top 40 under 40 Power List (2014) by The Analytical Scientist and the PhD Extraordinary Award in 2001 (UB).

Prof. Joan Ramon Morante received his PHD from University of Barcelona in 1980. He is full professor of the Faculty of Physics, University of Barcelona and director of the Catalonian Institute for Energy Research, IREC. His activities were centred in electronic materials and devices; semiconductors and electronics ceramics. He was also involved on nanomaterials for sensors, actuators and Micro and Nano systems, especially on chemical sensors. He is now focussed on "nano energy" addressing effort to the energy transfer mechanisms in solid interfaces involving electrons, photons and phonons as well as chemicals and photoelectrochemical processes. He has taken part in many R\&D EU projects (>30) as well as in private industrial projects. He has co-authored more than 600 works in international specialized journals with more of 13800 citations, several proposal patents 15) and he has been advisor of more than $35 \mathrm{PhD}$ students; he is member of international committees and editorial boards of scientific journals. He has been general chairman of international events and has been guest editor of many special issues. He has been awarded the Narcís Monturiol 
of the Generalitat of Catalunya, and the "senior research distinction" of the Generalitat of Catalunya. Actually, he was also vice president of the European Materials Research Society.

Pengyi Tang graduated in chemical engineering and technology at Hunan Normal University with a bachelor degree. And then he got a master degree of science in Lanzhou University in 2013 in China. In 2015, he started his PhD at Catalan Institute of Nanoscience and Nanotechnology (ICN2),

CSIC and The Barcelona Institute of Science and Technology in the Group of Advanced Electron Nanoscopy (GAe-N) under the supervision of Professor Jordi Arbiol at ICN2 and is co-directed by Professor Joan Ramon Morante from IREC on Advanced Electron Nanometrology Tools for Atomic Characterization of Energy Nanomaterials.

Prof. Cailing Xu received her Ph.D. degree in chemistry from Lanzhou University in 2006. She is currently a professor in college of chemistry and chemical engineering at Lanzhou University, China. Her research expertise lies in nanomaterials for electrocatalysis, biosensor, and energy storage and conversion.

Prof. Dr. Techn. Qingfeng Li is a full professor at Department of Energy Conversion and Storage, Technical University of Denmark (DTU). He received his Ph.D. in electrochemistry from Northeastern University, China, in 1990 and was awarded Doctor Degree of Technices at DTU in 2006. His research areas include proton conducting electrolytes, electrocatalysts and the related technologies, in particular, fuel cells and electrolysers.

Prof. Jan Fransaer is full professor in the Department of Materials Engineering at KU Leuven. He obtained his master in metallurgy at UGent and his $\mathrm{PhD}$ in materials engineering at $\mathrm{KU}$ Leuven. He was a postdoctoral fellow at Harvard, where he studied nucleation and phase transformations. His scientific activities focus on electrodeposition and electrochemical processing, energy storage, computational fluid dynamics and colloidal physics. 


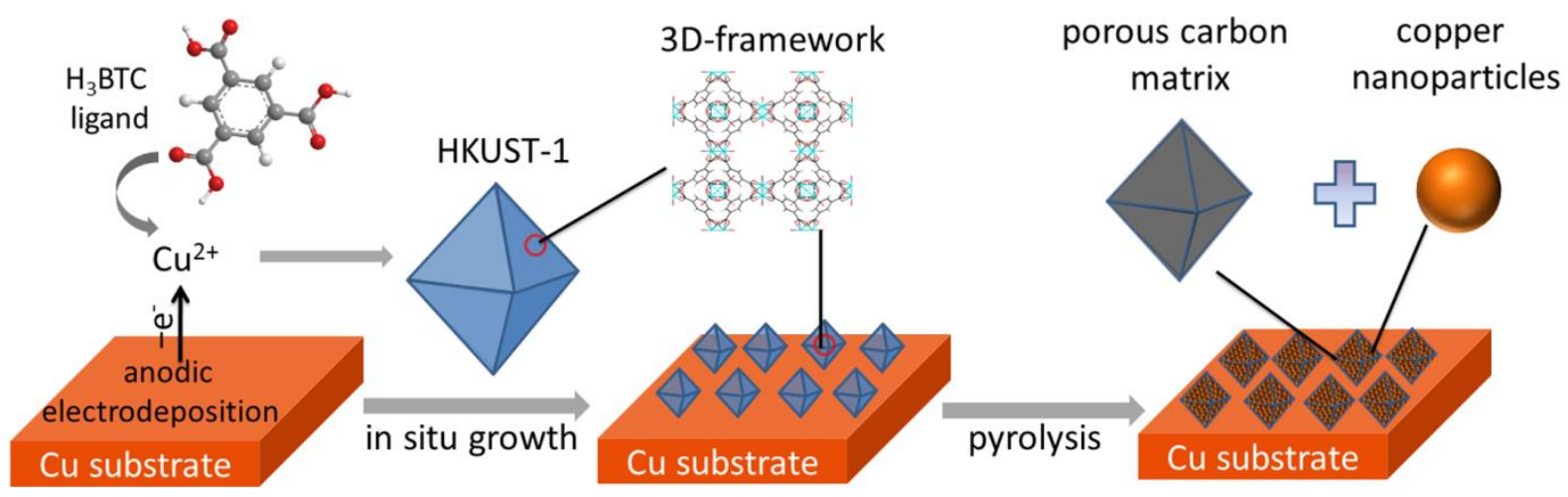

Figure 1. Schematic illustration of the synthesis of $\mathrm{Cu} @$ porous carbon matrix on the copper foam substrates. 


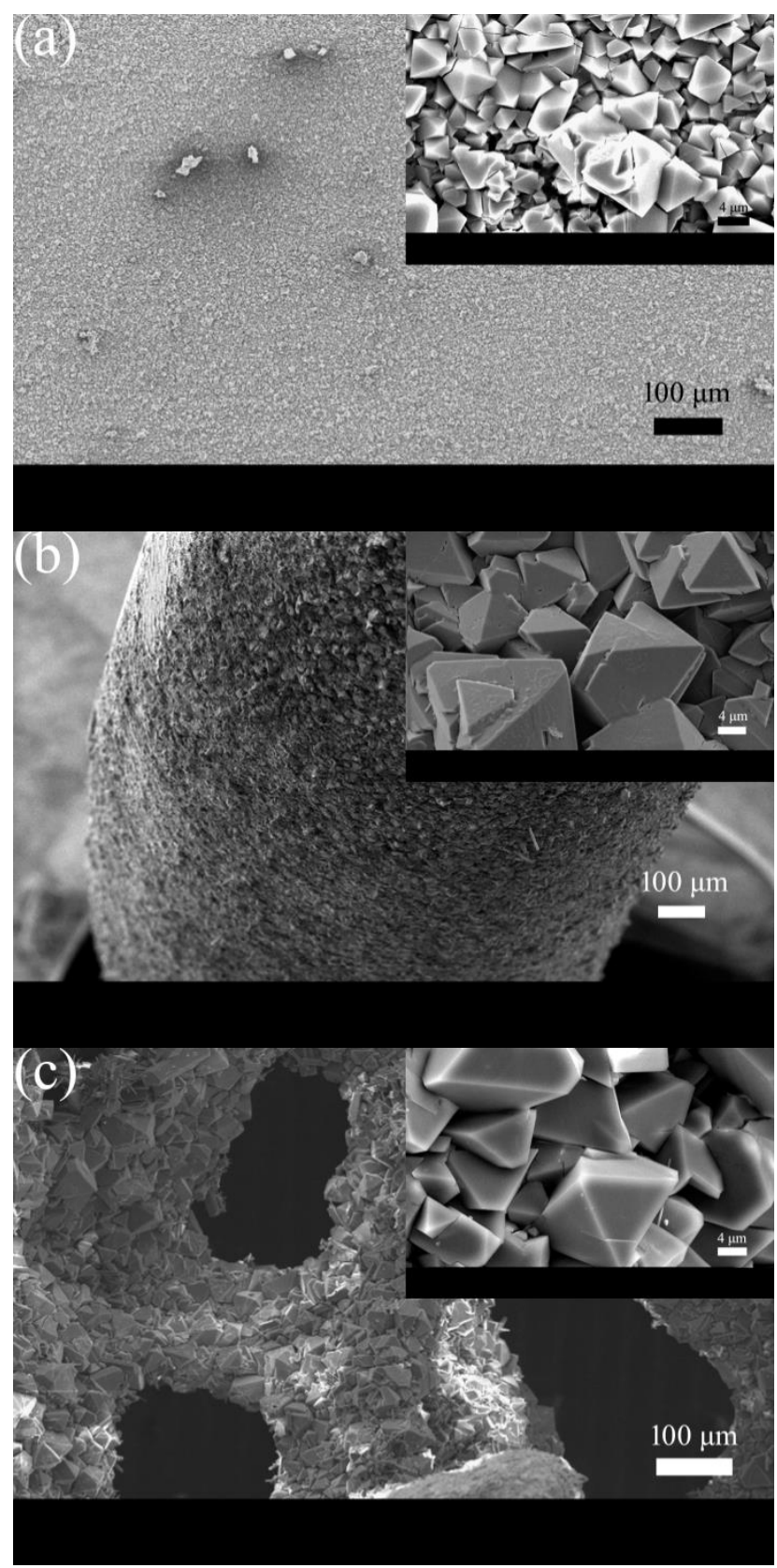

Figure 2. SEM images of different MOF-covered copper substrates: (a) copper plate; (b) copper wire and (c) copper foam. Insets are the corresponding magnifications with a scale bar of $4 \mu \mathrm{m}$. 


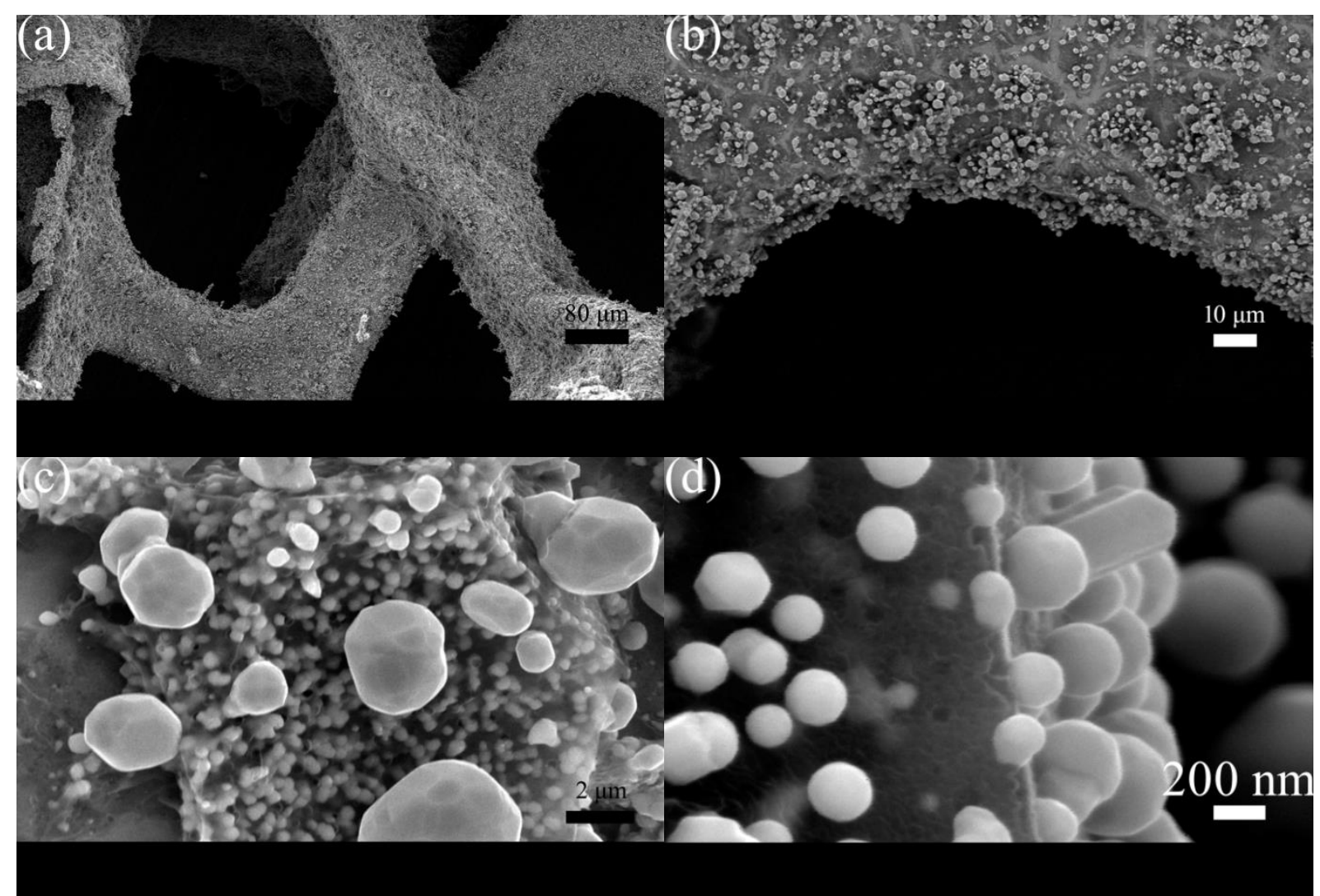

Figure 3. SEM images of the $\mathrm{Cu} @$ porous carbon matrix electrode at different magnifications. The scale bars are (a) $80 \mu \mathrm{m}$ (b) $10 \mu \mathrm{m}$, (c) $2 \mu \mathrm{m}$ and (d) $200 \mathrm{~nm}$, respectively. 


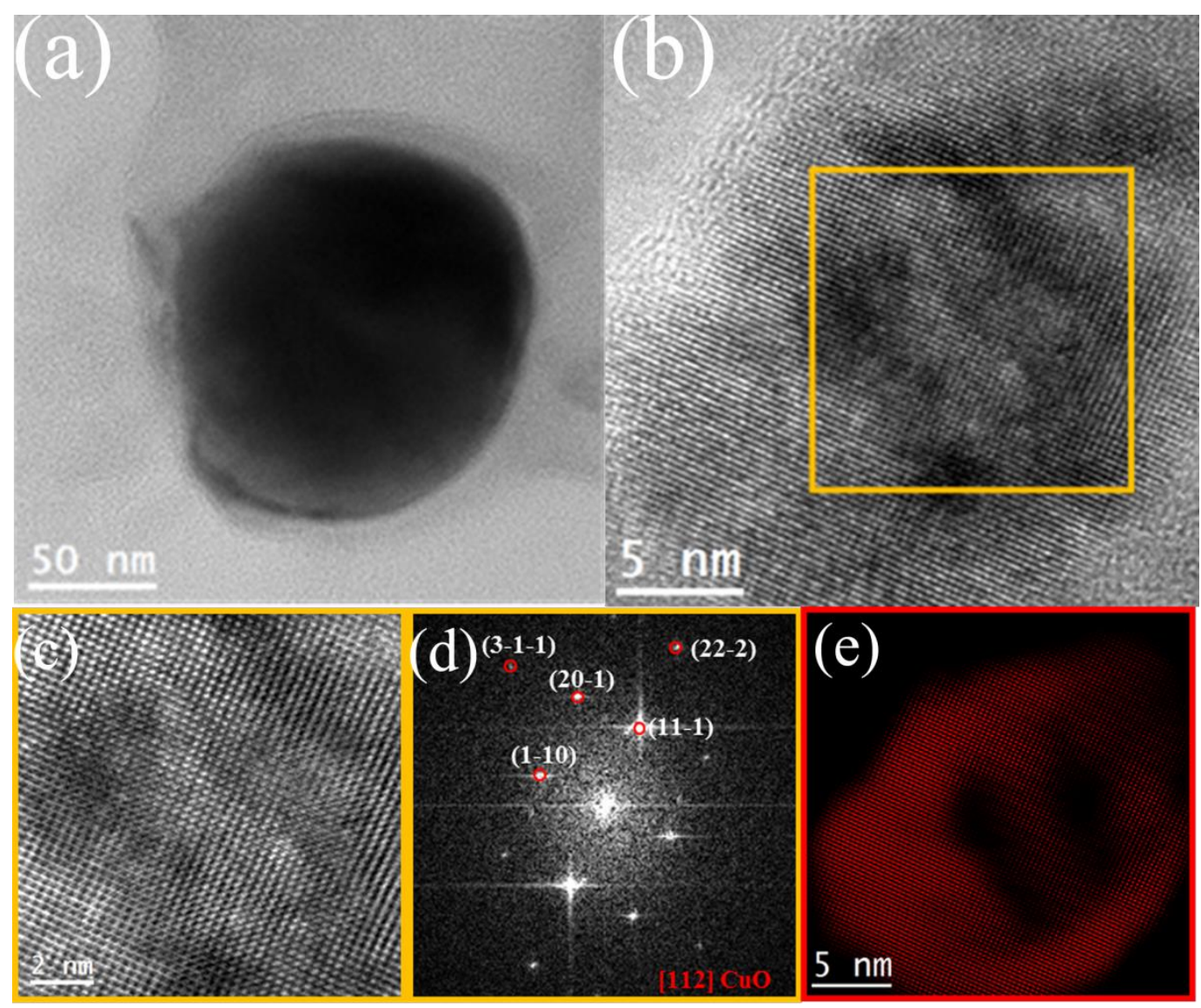

Figure 4. TEM images of $\mathrm{Cu} @$ porous carbon matrix materials (removed from the $\mathrm{Cu}$ foam) at the resolution of $50 \mathrm{~nm}$ (a) and $5 \mathrm{~nm}$ (b), respectively. (c) Details of the region squared in yellow and (d) the corresponding indexed power spectrum. (e) The RGB composition of IFFT from $\mathrm{CuO}$. 


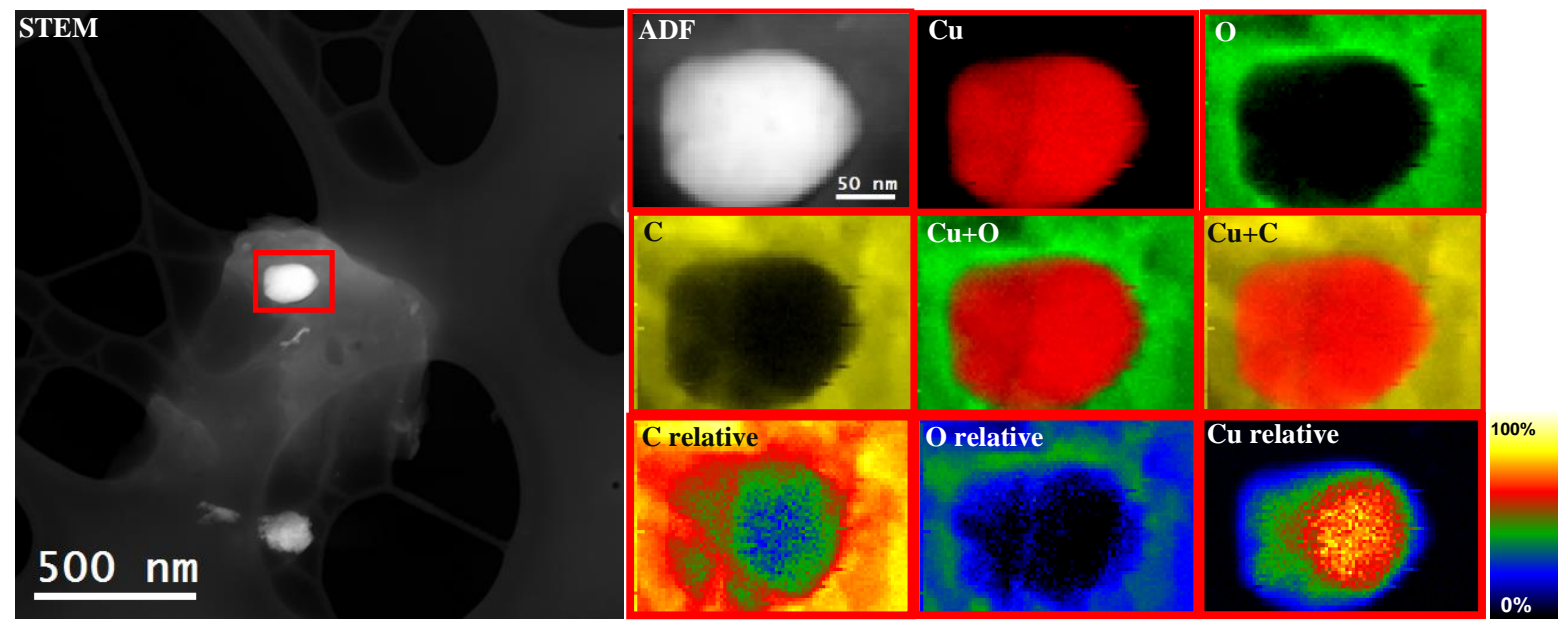

Figure 5. EELS chemical composition maps of $\mathrm{Cu} @$ porous carbon matrix materials (removed from the $\mathrm{Cu}$ foam) obtained from the area squared in red on the ADF-STEM micrograph. Right top and right middle: Individual $\mathrm{Cu}$ (red), $\mathrm{O}$ (green), $\mathrm{C}$ (yellow) maps and their composites; Right bottom: the relative composition map of $\mathrm{C}, \mathrm{O}$ and $\mathrm{Cu}$ elements. 

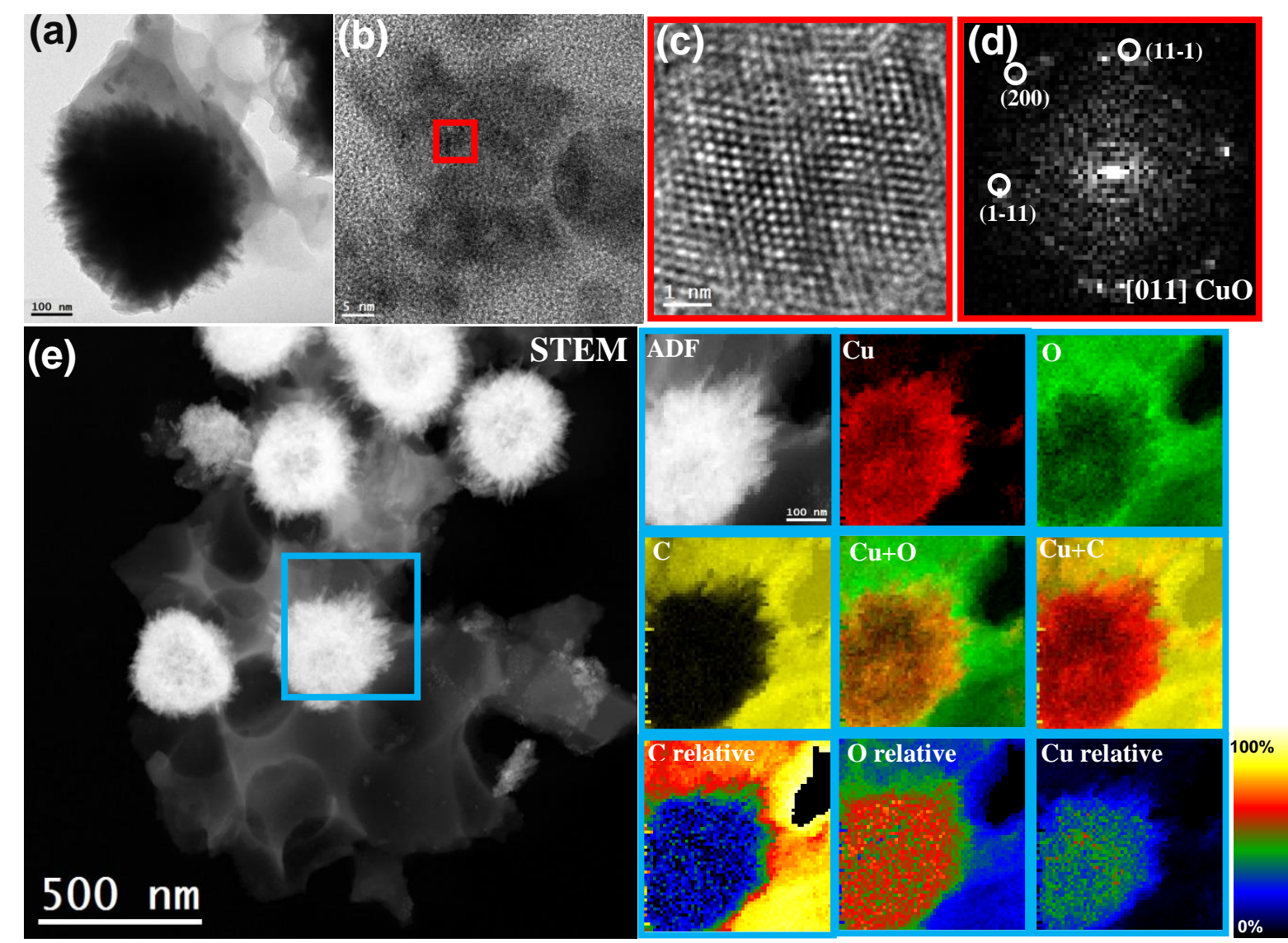

Figure 6. (a) and (b) TEM images of $\mathrm{Cu} @$ porous carbon matrix materials after sensor test (removed from the $\mathrm{Cu}$ foam). (c) details of the squared region in red line and (d) their corresponding indexed power spectrum. (e) EELS chemical composition maps of $\mathrm{Cu} @$ porous carbon matrix materials after glucose sensor test (scratched from $\mathrm{Cu}$ foam) obtained from the area squared in indigo on the ADF-STEM micrograph. Right top and right middle: Individual $\mathrm{Cu}$ (red), $\mathrm{O}$ (green), $\mathrm{C}$ (yellow) maps and their composites; Right bottom: the relative composition map of $\mathrm{C}, \mathrm{O}$ and $\mathrm{Cu}$ elements. 

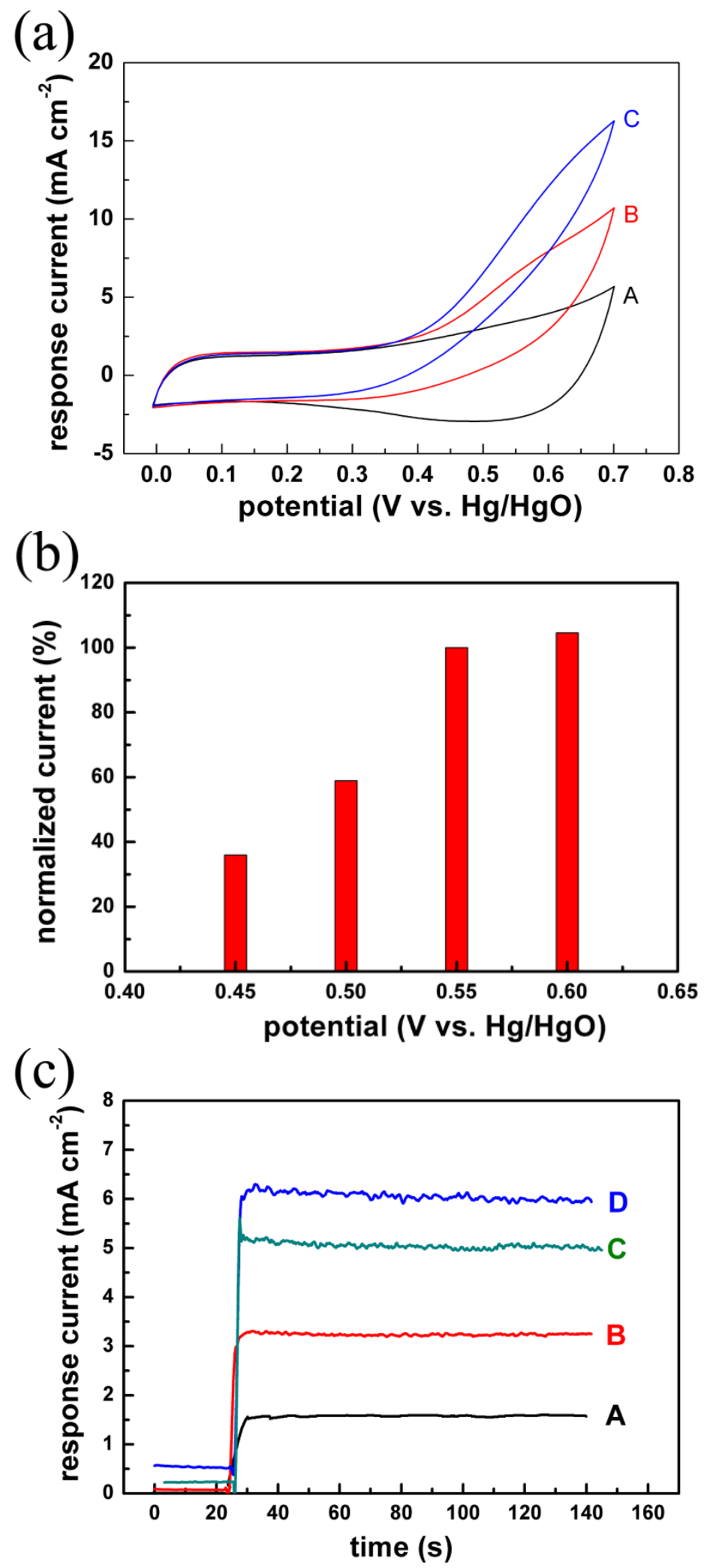

Figure 7. (a) CV curves of $\mathrm{Cu} @$ porous carbon matrix electrode in the absence (A) and presence of glucose (B: $1 \mathrm{mM}$ glucose; C: $2 \mathrm{mM}$ glucose) at a scan rate of $50 \mathrm{mV} \mathrm{s}^{-1}$, respectively. (b) Amperometric responses of $\mathrm{Cu} @$ porous carbon matrix electrode at potentials from $+0.45 \mathrm{~V}$ to $+0.6 \mathrm{~V}$ vs. $\mathrm{Hg} / \mathrm{HgO}$ to the addition of $1 \mathrm{mM}$ glucose (normalized by the amperometric response at $+0.55 \mathrm{~V}$ vs. $\mathrm{Hg} / \mathrm{HgO}$ ). (c) Amperometric responses of the copper plate electrode (A), copper foam electrode (B) and $\mathrm{Cu} @$ porous carbon matrix electrode $(\mathrm{C})$ to the addition of $1 \mathrm{mM}$ glucose at $+0.55 \mathrm{~V}$ vs. $\mathrm{Hg} / \mathrm{HgO}$. 

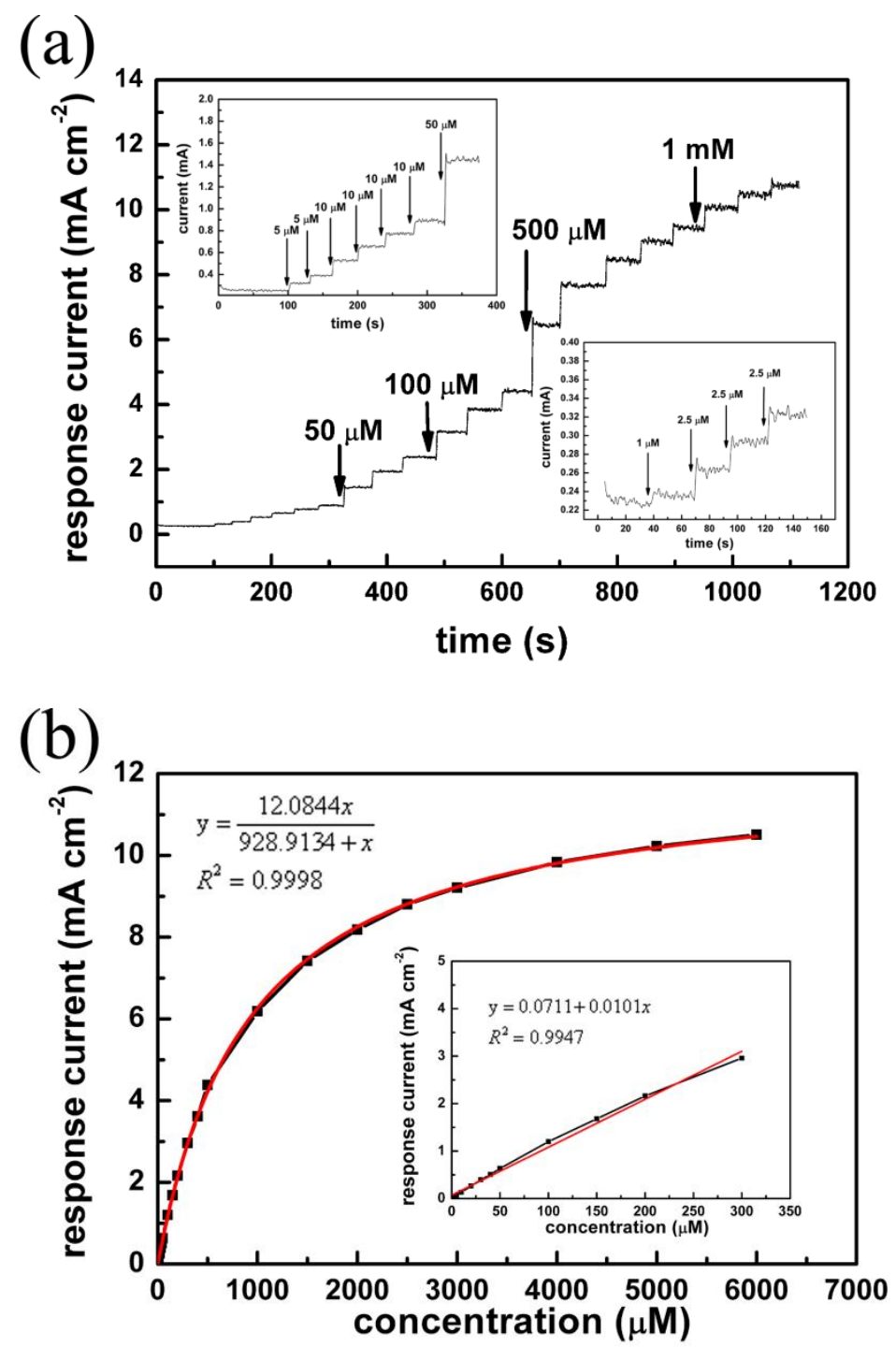

Figure 8. (a) Amperometric response of the $\mathrm{Cu} @$ porous carbon matrix electrode to successive additions of increased concentrations of glucose solutions to $0.1 \mathrm{M} \mathrm{NaOH}$ solution at an applied potential of $+0.55 \mathrm{~V}(v s . \mathrm{Hg} / \mathrm{HgO})$. The low-concentration part is magnified and shown in the inset in the upper left corner. The inset curve in the lower right corner is amperometric response of $\mathrm{Cu} @$ porous carbon matrix electrode to successive addition of glucose solution with smaller concentrations. (b) Corresponding calibration curve for Figure 8 (a). 


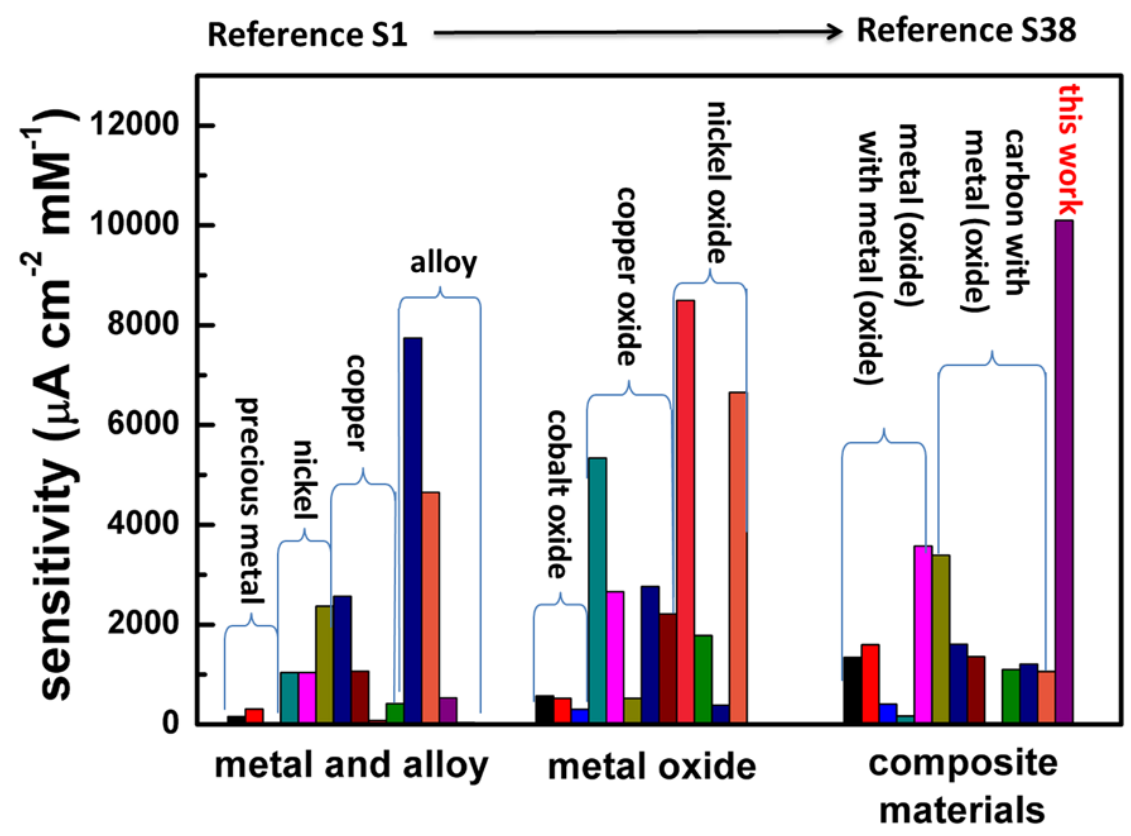

Figure 9. Comparison of the sensitivity of $\mathrm{Cu} @$ porous carbon matrix electrode with other electrodes reported in the literature (the related references S1 S38 are listed in the supplementary information). 
(a)

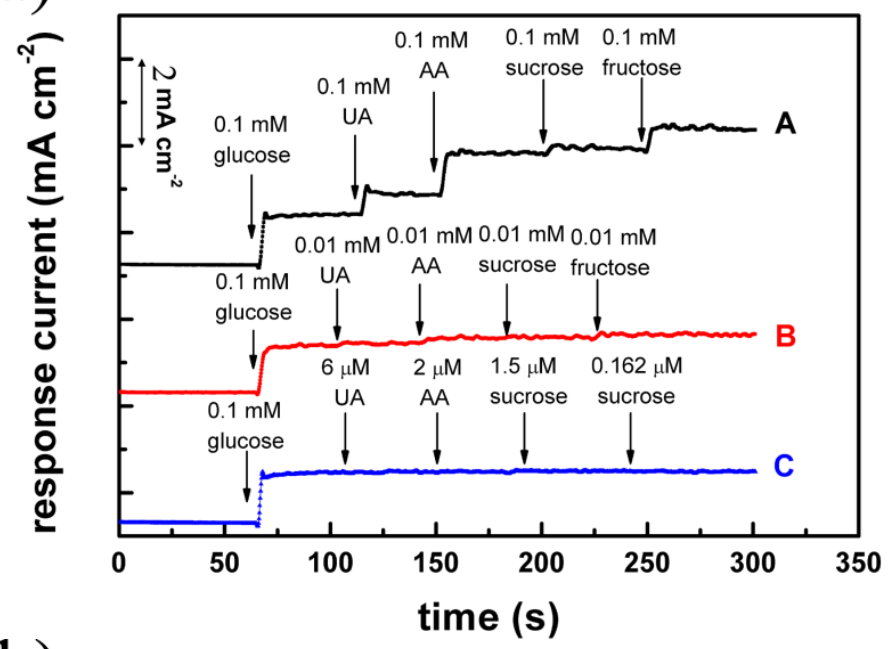

(b)

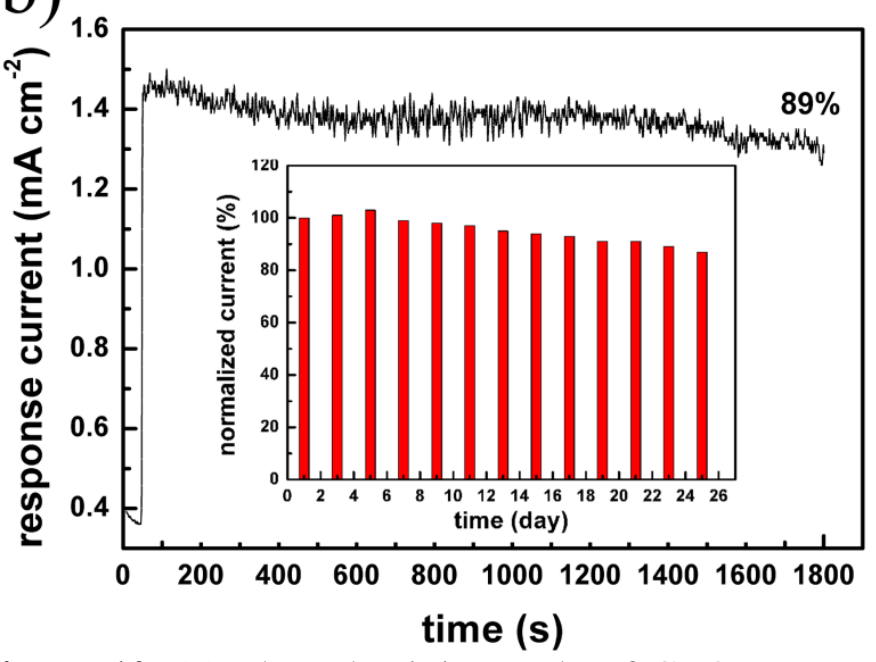

Figure 10. (a) The selectivity study of $\mathrm{Cu} @$ porous carbon matrix electrode with addition of different concentrations of UA, AA, sucrose, fructose and glucose at an applied potential of $+0.55 \mathrm{~V}$. (b) Long term stability of $\mathrm{Cu} @$ porous carbon matrix electrode at $+0.55 \mathrm{~V}$ for $1800 \mathrm{~s}$. Inset shows the normalized sensitivity of $\mathrm{Cu} @$ porous carbon matrix electrode to glucose tested every two days by amperometric measurement over 25 consecutive days. 